\title{
A Tentative Analysis of English Film Translation Characteristics and Principles
}

\author{
Yan Chang \\ Foreign Language School, Qingdao University of Science and Technology, Qingdao, China \\ Email: changyan27@163.com
}

\begin{abstract}
Film is a kind of audio-visual art, where dialogues work together with visual images, sound tracks and music. Film translation, as a kind of mass multimedia translation, is a new field of art and translation. Based on detailed analysis of the characteristics of film translation compared with general translation, two prevalent methods of film translation: dubbing and subtitling, and the constraints of each method, this paper attempts to categorize some feasible principles and requirements that account for successful film translation, which can be used to guide film translation practice.
\end{abstract}

Index Terms - film translation characteristics, constraint, translation principle

\section{INTRODUCTION}

Among the international exchange, film culture, especially film, has been promoted to be one of the dominant forms of culture in modern society. Extended beyond the field of art, it has become a part of people's lives and exerted a strong influence on the formation of people's language, living patterns and even values.

In order to appreciate the perfect original English film works, we have to resort to the translated ones. With such a big market and so huge an audience, film translation is undoubtedly one of the commonest forms of translation in our contemporary society.

Comparatively speaking, film translation is less studied both at home and abroad. In China, translators just carry out the studies of film translation according to their own intuition and experience in this field. Though several translators have proposed some theories of English-Chinese film translation, the research so far is neither systematic nor comprehensive; it remains one of the areas that need urgent research in translation studies.

"Film translation" has also been called "screen translation". But the term "screen translation" emphasizes the channel of the medium where the translation product appears, namely the TV, cinema, or video screen; while "film translation" emphasizes the dimensions of the communicative mode. Unlike communication through books, radios, telephones, or sign language, film communication implies that both the acoustic channel through air vibrations and the visual channel through light waves are simultaneously utilized. It stresses the need to accommodation in the process of translation the requirements of both these channels.

\section{Characteristics OF Film Translation}

\section{A. Multimedia}

Film, is a kind of multimedia, both a visual medium and an aural one. In general translation, the readers see it with their eyes, but read it in mind. They get messages only by a visual channel. The audience of film watch what characters are doing and hear what they are talking about, messages reach the audience through visual and acoustic channels. Obviously, fascination of dubbed film lies in harmonious cooperation between visual and acoustic channels, which demands the target language should cope with the original images in the film as naturally as possible.

What's more, films and TV plays are supposed to act directly on the sense of sight of the audience, not on the sense of hearing. As Martin points out, "Picture is the basic element of the language of film." "However... it is normal and unquestionable that in the film utterance forms a constituent element of the reality and play a fundamental role in achieving realism... In fact, utterance is a component of the visual picture and therefore, it is subject to the movement of the pictures."(Martin, 1977, p. 149) We can notice that the translation of utterance should be synchronized with the settings of the scenes, the identity of the characters, their movements, gestures, facial expressions, pauses and lip movements; in that pictures transfer the major part of the messages and pictures play the much more important role.

\section{B. Spoken Language \& Easy Understandability}

English feature films are an entertainment more than a holy art. Once they indulge in self-admiration, they come to a dead end. As a mass art, feature films are due to win the audience. An excellent film should be a dignified compromise between market and art so as to offend neither the mass nor the critics.

Film translation primarily deals with spoken language, rather than written language. English films are means of entertainment, so it is the translator's duty to enable the audience to get entertained in the easiest way. The audience 
may be experts of English culture or merely laymen; they may be Doctors or just beginners. They have different ages, genders, levels of education and backgrounds, etc. They consequently have varied understanding abilities and appreciation values. To cater so many different tastes, popular films assure well-chosen themes, closely-knit plots, attractive frames and most importantly, easily understood dialogues.

With dialogue being the major component of the script, colloquialism is the top priorities for a translator of film translation.

In addition, extra-linguistic features such as facial expressions, gestures, stance and paralinguistic features such as pitch of the voice, rapidity of speech, pauses and hesitations should also be taken into account in film translation.

\section{Transience}

In film, utterances are spoken which are difficult to trace. In general translation, to be more specific, fiction readers may turn over pages to ransack any useful clues with ease and in no hurry when failing to grasp the intended meaning. However, if the audience miss what they are hearing, especially important sentences or words, they will be lost in the dark, because they has nowhere to turn to, and no time to think with new messages surging over them. The "shots" of films last only seconds and usually cannot be replayed, which makes it impossible for the audience to refer back to the previous parts of the story to recollect or reflect upon the information as a reader does with a book. The transience of pictures demands the translator convey as much message as the duration of each "shot" allows, and at the same time as intelligible enough for the audience to absorb immediately as possible. What's more, no notes can be allowed on the screen as other translators do in a book to explain potential linguistic obscurities and cultural specifics. The translator is forced to lighten the burden on the audience, which keeping the original message intact.

\section{The Feedback Effect}

Apart from having to face the time-and-space constraints of the film media, the film translator never escapes the fact that there is always someone, in most cases at least a large minority of his viewers, who understands very well what is said by the people on the screen (Gottlieb, 1997). Subtitling is seen as overt translation, laying itself bare to criticism from everyone with the slightest knowledge of the source language (Gottlieb, 1994). The viewers' reception of a subtitled program is based on the interactive subtitles-picture, with the dialogue playing a pivotal role. In a number of cases, such feedback is felt by translator and viewer as negative. However, in other situations the feedback from the original version is of a positive nature. Movies, being poly media, presents the translator with many deictic solutions to potentially ambiguous utterances: the subtitler can actually see or hear how a certain linguistic feature should be interpreted.

\section{E. Complicated Procedure}

Compared to general translation, film translation has a more complicated procedure. General translation follows the traditional translation pattern:

Author $\rightarrow$ the original $\rightarrow$ Translator $\rightarrow$ Translated Text $\rightarrow$ Receptors

The author and the original are the focuses in this procedure. The translator, as the first receptor of the original, reads thoroughly the original text, and then represents it to the receptors in the target language. The translated text will undoubtedly affect the receptors' evaluation and understanding of the original one. So receptors' reception to the translation servers as feedback that the translator can never afford to neglect. Author, translator and receptors are the subjects affecting the whole procedure. And the original and translated texts are the tool and vehicle of their mental emotional communication.

The procedure of film translation is more complicated as follows: [Dubbing]

[Author] $\rightarrow$ the original $\rightarrow$ Translator $\rightarrow$ Translated Screenplay $\rightarrow$

Dubbing Director (Dubbing Actors) $\rightarrow$ Dubbed Screenplay $\rightarrow$ Audience

Actually the scriptwriter replaces the author, who is ignored by the audience and by translation researchers. No one has ever thought of checking on his life story and his accustomed styles as they do in general translation, fiction translation. Usually film scripts are translated as if independent of any writer. Film script translation has to be tested for its harmony with visual frames. In the later stage of production, dubbing actors and director join in the procedure. Dubbing director is the one in charge of guiding dubbing actors to a correct and faithful performance. The translated script undergoes considerable changes in this stage. Finally, the new soundtrack in the target language is dubbed onto the film. Thus we can sense that film translation is, by all means, of more complicated creation, which consists of more components and elements.

\section{F. Little Chance of Retranslation}

As we all know, a good classical novel has always been viewed as the most valuable cultural heritage. People in different times can possibly read out of it endless new meanings. That's why it is often the case that an old novel has more than one translated versions, still with more to come in the future. However, a feature film is seldom translated twice. Feature film translation bears resemblance to fast food, quickly consumed and quickly forgotten.

\section{Classification OF Film Translation}


Dubbing and subtitling are the most prevalent methods of film translation used to make foreign-language programs available to the domestic market according to different communication channels.

\section{A. Dubbing}

Dubbing or lip-sync dubbing as a specific technique attempts to cover entirely the spoken source text with a target text adjusted to fit the-visual-lip movements of the original utterances. (Karamitroglou, 2000)

Dubbing, which is sometimes called (post-) synchronization, is the replacement of the dialogue and narration in a foreign language into the language of the viewing audience, the target language. Dubbing is the method in which "the foreign dialogue is adjusted to the mouth and movements of the actor in the film, and its aim is seen as making the audience feel as if they were listening to actors actually speaking the target language.

Dubbing involves a translation of speech into writing. It is the oral translation of spoken language. Dubbing also requires the substitution of the voice of each character on the screen by the voice of an actor, that's why some highly invested films invite pop stars to be the dubbing actors to attract the audience's interest. With dubbing, the translation is covert and the audience hears the target language dialogue, and is completely shielded from the foreign tongue.

Before the 1940s, with dubbing, all the original soundtracks in the film have to be erased, which with no doubt decrease the audience's illusion of authenticity. But Dr. Fotios Karamitroglou, a member of ESIST (the European Association for studies in Screen Translation) says that with the help pf digitalization, dubbing seems to have a better future. Firstly, the ability to have the voices of the original actors on separate tracks allows us to retain the original background sound, as well as the music and effects, and opt for smooth blending with the original images. Secondly, since lip-sync has been regarded as a most difficulty in film translation, dubbing is also enhanced by our recently acquired ability to interfere with the original image. (Karamitroglou, 2000) The procedure that the Japanese animators follow to change the lip movements of their drawing in order to synchronize them to a French script has already drawn the attention of advertising companied $\backslash$ s as well as individual film producers.

\section{B. Subtitling}

As explained in the New Oxford Dictionary of English, "subtitles are captions displayed at the bottom of a cinema or television screen that translate or transcribe the dialogue or narrative" They are "the words printed or superimposed on a film in foreignlindistinguishable regional language in order to translate what is being said on the sound track." We can find that subtitles are pasted to the original visual images and sometimes cause minor losses of the integrity of original pictures.

Subtitling can be defined as the translation of the spoken (or written) source text of a film product into a written target text which is added onto the images of the original product, usually at the bottom of the screen (Karamitroglou, 2000). The concept is sometimes used synonymously with "captioning" (to add caption at the foot of the screen). (Minchiton, 1987, p.282)

According to the positions in the film, subtitles can be categorized into three types. Those appearing at the beginning of the film include the film title, director, leading actor(s), or actress(es), major production members and they are called "open credit titles"; those appearing after the main feature film include detailed cast and production members, sponsors and many other production information and usually called "end credit titles"; the rest of the main subtitles cover the main feature film and they are called "the main subtitle". According to specific functions in the entire film, main subtitles can be further categorized into spoken subtitles, film subtitles with music, graphical subtitles, etc.

\section{Comparison of Dubbing and Subtitling}

1. Authenticity. Among all kinds of film translation, dubbing is the one that interferes the most in the structure of the original. Many critics raise objections as to its authenticity.

However, subtitling involves the least interference with the original; in other words, it is the most neutral, minimally meditated method. Therefore, it is subtitling that contributes to experiencing the flavor of the foreign language, its mood and the sense of a different culture more than any translation mode. Plainly speaking, the audience enjoys the whole original film including sound and image, with the help of subtitles.

Dubbing is known to be the method that modifies the source text to a large extend and thus makes it familiar to the target audience through domestication. Its aim is to make the audience feel as if they were listening to actors actually speaking the target language. subtitling, i.e. supplying a translation of the spoken source language dialogue into the target language in the form of synchronized captions, usually at the bottom of the screen, is the form that alters the source text to the least possible extent and enable the target audience to experience the foreign and be aware of its "foreignness" at all times.

2. Cost. Because of the technical difference between dubbing and subtitling, the difference in cost is huge: subtitling is 10-15 times cheaper than dubbing. (Luyken et al., 1991) On the whole, it can be stated that especially in Western European countries dubbing is preferred in larger and more affluent countries, which can expect high box office receipts, whereas subtitling is used in small countries, whose audiences comprise more restricted markets. According to Minchiton, "Dubbing is much more expensive and time consuming than subtitling." (Minchiton, 1987, p.279)

3. Non-verbal information. It is frequently the case that there appear some non-verbal signs, e.g. notices, tokens, trademarks or road signs in the background during the course of a film. All these seem to give away dubbing which 
attempts to function as the original. At this time, subtitling can be useful to explain the meaning of the sign and to help them to accomplish their functions (maybe very essential functions) within the entire plots by inserting a subtitle with the target language equivalent (e.g. in capital letters or italics to differentiate it from spoken utterances)

\section{CONSTRAints OF Film TRANSLATION}

In the process of translation, many factors contribute to the realization of an optimally approximated translation. Film translation, is no exception, which imposes a variety of constraints on the translator. Unlike other types of translation, film translation does not allow free condensation or deletion. It has stricter demand on completeness and logic. A movie is always originally film art concentrated in about two hours, as well as a closely woven fabric from which nothing can be removed. All frames are linked with each other, parts of plots echoing from afar. One part missing, the whole is hit.

Film translation, is also called "film synchronization" by some experts. They take into account the more specific question of synchrony, as well as technical constraints that the manipulation of film materials implies. When dealing with the translation of the original film script, Mayoral, Kelly and Gallardo (Mayoral, Kelly and Gallardo, 1988, p.359) put forward the following types of synchrony:

Synchrony of time: agreement in time of different signals that communicate a unit of information.

Spatial Synchrony: the signals occupy neither more nor less space than that which corresponds to them.

Content Synchrony: the meanings transmitted by different signals contradict neither each other nor the whole message.

Phonetic Synchrony: synchrony of sound signals of spoken dialogue with the visible speech movements on the screen.

Character Synchrony: the harmony between the image of the character and his or her voice and words.

Obviously, subtitling is mainly conditioned by synchrony of time and spatial and content synchrony, while dubbing also must take into account the phonetic and character synchrony.

The following is the specific constraint study of the two classes of film translation.

\section{A. Constraints in Dubbing}

Unlike the audience of the original, dubbing audience see the visual part of the original, but hear the dubbed dialogue in their own native language, with the make-believe acknowledgement that the language are just the kind the characters are speaking. So lip synchronization is usually seen as the strongest constraint on accurate translation. The script translator modifies each utterance in order to match it with the lip movements of the person seen on the screen.

Indeed it is difficult to find target language words to match the source language lip movements. Lip synchronization can be better performed with a more pragmatic plot-oriented translation. If translation aims at conveying the general tone of each scene rather than locating meaning in each sentence, there will be more freedom to find appropriate words for lip synchronization.

What's more, there should be a strict equivalence of extra-linguistic features of voice, especially gender and age. Other markers of speech such as personality, class and ethnicity are most difficult because these features are not universally available or comparable. Dubbing should also be consistent with the performances; so another requirement is the compatibility of the dubber's voice with the facial and body expressions, such as pause, stress and gesture, visible on the screen.

\section{B. Constraints in Subtitling}

The ideal in subtitling is to translate each utterance in full, and display it synchronically with the spoken words on the screen. However, the medium imposes serious constraints on full text translation.

1. Space limitations

No matter how big the size of the film screen, subtitles can only occupy the space of at most two lines at the lower part. However, the subtitles should be enough to transfer the necessary message and information. Each subtitle should be able to accommodate a satisfactory portion of the (translated) spoken text and minimize the need for original text reduction and omission. It is reported that, for ideographic language subtitling, such as Chinese, Japanese and Korean, each line allow no more than 18 characters. Overspreading of more characters would reduce the legibility of subtitles.

2. Constraints on duration

The presence of subtitles should be consistent with the visual images, and they should also be long enough for average viewers to catch the meaning. At the same time, they should not be too long on the screen; otherwise, the viewers will be annoyed.

Guardini holds that the time of presentation of subtitles is dictated by a) the duration of the utterance in the original version; b) the reading speed of the audience; c) the visual information given on the screen, which also needs to be perceived clearly by the viewers; and d) the editing style adopted in the film. To make addition, it also depends on the quantity and complexity of the text, the speed of the dialogue and the necessary intervals between subtitles.

According to Karamitoglou, the reading speed of the "average" viewers (aged between 14-65, from an upper-middle socio-educational class) for a text of average complexity (a combination of formal and informal language) has been proven to range 150-180 words per minute, i.e. between $2.5-3$ words per second. In all the 
above-mentioned situations, the duration time should not be added in order to avoid the acoustic re-reading of the subtitles, especially by faster readers. In cases where the text is lexically and syntactically easy to process or the past pace of the film action dictates a reduction in the duration of the subtitles, the duration time could be calculated and shortened down to the maximum of the reading time ( 3 subtitled words per second or $1 / 3$ of second per subtitled word). (Karamitoglou, 2000) As a result, the translator often presents the source language dialogue or narration in condensed form. Loss or change of meaning also happens because the written text cannot transfer all the messages and information of the spoken language in limited time. Thus this is one of the exploration-needing problems.

In all, film synchronization is by no means of an easy thing. It is complicated because of not only traditional requirements, but also the special technical constraints in multi-media translation domain should be considered for integrality.

Nowadays as the digital technology develops so quickly, almost all foreign language film products have diverse choices of different soundtracks. We can choose either one soundtrack for dubbing or another for subtitling, or even mixed soundtrack for both effects at the same time. In this case, in this dissertation, I will take film translation as a certain translation to meet both requirements, so I will take the constraints and characteristics of both translation modes into consideration along side.

\section{SPECIAL PRINCIPLES FOR FILM TRANSLATION}

\section{A. Synchronization (for the Company of Other Integral Parts of Film Elements)}

Film is a kind of art in nature, and it is also the translator's task to represent the artistic constituents in the original to the target audience. Some experts call film translation "film synchronization". Here we make emphasis on its extralinguistic and paralinguistic factors in film dialogue. We take into account lip rounding, timing, pause, gesture, facial expression and even sometimes picture order to achieve synchrony of spoken language with the visible speech movements and shifts of pictures on the screen. There must be a general match between the characters' visual presentation and their verbal expression. At this time, rearrangement and reduction are very useful strategies.

\section{B. Colloquialism and Naturalness (for the Realness of Art and the Authenticity of Life)}

Nearly all the languages in film are colloquial languages in forms of either monologue or dialogue. And of course, there are some exceptional cases, for example, some written forms of the texts such as wills, contracts, formal announcements and so on. Thus the orality is the priority in film translation. High degree of parallelism, the loose paratactic sentence structure, the predominance of co-ordination and the paucity of subordination are found to be characteristic of unplanned spoken discourse.

Translated speech should be as natural as possible, this is the basic thing for the audience to understand and also appreciate the film in the same way as the original audience does. In translated version, we'd better choose high frequency words or phrases, short sentences. By naturalness, we mean the translated dialogues should be also accorded with the audience's speaking habits. The addressees should be "speaking in the target language" naturally just as the audiences do.

\section{Legibility (for the Target-audience Orientation)}

Translators should attach great importance to the forms understood and accepted by the audience for which a translation is designed. We are not content merely to translate so that the average receptor is likely to understand the message rather we aim to make certain that such a person is unlikely to misunderstand it. Because of film dialogue's transience feature, we also emphasize easy understandability - read or hear on the basis of soft touch. The translated version must re-construct an acoustically coherent and complete film discourse. The translated dialogues must be suitable for film performance, comprehensible to the contemporary audience.

As far as this paper is concerned, to put all the principles into full, translators could adopt translation strategies flexibly according to different circumstances. Different strategies such as imitation, expansion, condensation, rearrangement, paraphrase and reduction could all be adopted as long as they are helpful.

\section{CONCLUSION}

With the enlargement of cultural exchange, more and more English films have been introduced into China. Film, as a special audio-visual art of mass media, establishes a multi-channel and multi-code type of communication.

Since film is kind of film art form, taking into consideration the characteristics of film translation will be most helpful for film translation study. Compared to general translation, film translation has its peculiar characteristics. In details, the characteristics of film translation are: multimedia, spoken language and easy understandability, transience, the feedback effect, more complicated procedure and little chance of retranslation.

Film translation, according to actual method, can be divided as dubbing and subtitling. And each has its own characteristics and constraints. As for dubbing, the target audiences hear another verbal system rather than the original dialogue, they take the acknowledgement that the characters are just "speaking" the language like the target audience themselves. Facial and body expressions, such as lip movements, gestures, pauses, stress, even the gender and age of 
the voices, should be thought about in dubbing. As for subtitling, the main constraints are space limitation and limitations on duration.

In view of these analyses, this paper probes into the special requirements of film translation, and tentatively proposes special principles to obtain success of film translation-Synchronization, Colloquialism and Naturalness and Legibility

However, there is still much to be done for further development of the theory of film translation about both the principles and concrete strategies. In order to put these principles into employments, many specific strategies should be appropriately chosen and flexibly adopted according to different circumstances so as to get more appropriate and artistic translated versions of foreign films.

\section{REFERENCES}

[1] Basil, Hatim \& Ian Mason. (1997). The Translation as Communicator. London: Rouledge.

[2] Bassnett, Susan. (1991). Translation studies. London: Methuen.

[3] Bell, A. (1984). Language style as audience design. Language in Society 13, 145-204.

[4] Catford, John C. (1965). A linguistic theory of translation. London: Oxford University Press.

[5] Danan, Martine. (1991). Dubbing as an expression of nationalism. Meta 36.2, 16- 36.

[6] Gambier, Yves \& Henrik Gottlieb eds. (2001). (Multi-) Media Translation: Concepts, Practices, and Research. Amsterdam: J. Benjamin.

[7] Gottlieb, Henrik. (1994). Subtitling: diagonal translation. Perspectives: Studies in Translatology 2.1, 12-15.

[8] Gottlieb, Henrik. (1997). You got the picture? On the polysemiotics of subtitling wordplay. In Delabastita, Dirk (ed), Traductio. Essays on punning and translation (vol. 8). Namur: St. Jerome \& Presses Universitaires de Namur, 106-124.

[9] Karamitroglou, Fotios. (2000). Towards a methodology for the investigation of norms in audiovisual translation. Amsterdam-Atlanta: Rossipi B.V.

[10] Lefevere, Andre, ed. (1990). Translation, history and culture. New York: Rouledge Inc.

[11] Luyken, Georg-Michael et al. (eds). (1991). Overcoming Language Barriers in Television: Dubbing and Subtitling for the European Audience. Manchester: European Institute for the Media.

[12] Martin, M. (1977). The Languages of films. Beijing: China Film Press.

[13] Mayoral Asensio, Roberto, Dorothy Kelly \& Natividad Gallardo. (1988). Concept of constrained translation: Non-linguistic perspectives of translation. Meta 33.3, 356-367.

[14] Minchiton, John (1987). Fitting titles. Sight and Sound 56, 279-282.

[15] Newmark, Peter (2001). Approaches to translation. Shanghai: Shanghai Foreign Language Education Press.

[16] Nida, Eugene A. (2001). Language, culture and translating. Shanghai: Shanghai Foreign Language Education Press.

[17] Nord, Christiane. (2001). Translation as a purposeful activity. Shanghai: Shanghai Foreign Language Education Press.

[18] Remael, Aline (2001). A place for film dialogue analysis in subtitling courses. Linguistica Antverpiensia 35, 59-85.

Yan Chang was born in Jingzhou, China in 1981. She received her M.A. degree in foreign linguistics and applied linguistics from Ocean University of China in 2006.

She is currently a lecturer in the School of Foreign Languages, Qingdao University of Science and Technology, Qingdao, China. Her research interests include linguistics, English rhetoric and translation. 